\title{
Association of Physical Activity with the Incidence of Atrial Fibrillation in Persons >65 Years Old: The Atherosclerosis Risk In Communities (ARIC) Study
}

Grace Fletcher, MPH, ${ }^{1}$ Aniqa B. Alam, MPH, ${ }^{1}$ Linzi Li, MPH, MSPH, ${ }^{1}$ Faye L. Norby, PhD, MPH, ${ }^{2}$ Lin Y. Chen, MD, MS, ${ }^{3}$ Elsayed Z. Soliman, MD, MSc, MS, ${ }^{4}$ Alvaro Alonso, MD, $\mathrm{PhD}^{1}$

${ }^{1}$ Department of Epidemiology, Rollins School of Public Health, Emory University, Atlanta, GA, USA.

${ }^{2}$ Department of Cardiology, Smidt Heart Institute, Cedars-Sinai Health System, Los Angeles, CA, USA.

${ }^{3}$ Cardiovascular Division, Department of Medicine, University of Minnesota Medical School,

Minneapolis, Minnesota, MN, USA.

${ }^{4}$ Epidemiological Cardiology Research Center, Department of Medicine, Section on Cardiovascular Medicine, Wake Forest School of Medicine, Winston-Salem, NC, USA.

Corresponding author: Alvaro Alonso, MD, $\mathrm{PhD}$, Department of Epidemiology, Rollins School of Public Health, Emory University. 1518 Clifton Rd, CNR \#3051, Atlanta, GA 30322. Phone: +1 404727 8714/ Email: alvaro.alonso@emory.edu 


\begin{abstract}
Background: Though moderate levels of physical activity (PA) seem to reduce the risk of atrial fibrillation (AF), the association of PA with AF in the elderly remains unclear.
\end{abstract}

Methods: We studied 5,166 participants of the Atherosclerosis Risk in Communities (ARIC) cohort that took part in visit 5 (2011-2013), were free of AF and had complete information on all variables. Selfreported PA was evaluated with a validated questionnaire and weekly minutes of leisure-time moderate to vigorous physical activity (MVPA) were calculated and categorized using the 2018 Physical Activity Guidelines for Americans (no activity [0 min/week], low [ $>0-<150 \mathrm{~min} / \mathrm{week}]$, adequate $[150-<300$ $\mathrm{min} / \mathrm{week}]$, high [ $\geq 300 \mathrm{~min} / \mathrm{week}])$. Incident AF between the visit 5 and the end of 2019 was ascertained from hospital discharges and death certificates. Cox models were used to calculate hazard ratios (HR) and 95\% confidence intervals (CI) for AF by levels of physical activity adjusting for potential confounders.

Results: The mean (SD) age for the sample was 75 (5) years; $59 \%$ were female and $22 \%$ were Black. During a mean (SD) follow-up time of 6.3 (2.0) years, 703 AF events were identified. The association of MVPA with AF incidence showed a U-shaped relationship. Compared to those not engaging in MVPA, individuals with low MVPA had a $23 \%$ lower hazard of AF $(\mathrm{HR}=0.77 ; 95 \%$ CI: 0.61, 0.96), while those with adequate MVPA had a 14\% lower hazard (HR 0.86; 95\% CI: 0.69, 1.06). High levels of MVPA were not associated with AF risk (HR 0.97; 95\% CI: 0.78, 1.20). There was no evidence of heterogeneity when stratified by race and sex.

Conclusion: This study suggests that being involved in low to moderate levels of MVPA was associated with a reduced hazard of AF. There was no evidence of increased risk of AF in those with higher levels of MVPA.

Key Words: atrial fibrillation, physical activity, elderly 


\section{INTRODUCTION}

Atrial fibrillation (AF) is one of the most common cardiac arrhythmias found in developed countries. ${ }^{1}$

Older age, as well as the presence of cardiovascular risk factors such as hypertension, obesity and diabetes, have been consistently linked to an increased risk of being diagnosed with $\mathrm{AF}^{2}{ }^{2}$ Lifestyles may also play a role in the development and prevention of $\mathrm{AF}^{3}$ In particular, multiple studies have evaluated the impact that physical activity (PA) has in the development of AF. Meta-analyses of these studies suggest a U-shaped association between PA and AF risk, with lower risk among individuals engaged in moderate levels of physical activity but no benefit with higher levels, compared to those with low levels. ${ }^{4}$

${ }^{5}$ In fact, individuals engaging in high-endurance PA (e.g. long-distance runners and skiers, professional cyclists) seem to have a higher risk of developing AF. ${ }^{6}$ These observations suggest a complex relationship of PA levels and intensity with AF risk.

AF risk is particularly high among persons 65 and older. The evidence on the effects of PA on AF risk in this age group, for which preventive interventions would have the highest impact, is limited. An analysis of the Cardiovascular Health Study, including 5446 persons older than 65 (mean age 73), found an inverse linear association between leisure time PA and AF risk, but a U-shaped association between exercise intensity and AF, with lower AF risk associated with moderate-intensity exercise but not with high-intensity exercise. ${ }^{7}$ Additional studies on the association of PA with AF risk in older individuals, particularly among racially diverse populations, are needed to inform preventive guidelines in this highrisk population.

Thus, to address existing limitations of the literature and provide additional evidence that could inform preventive recommendations in older individuals, we evaluated the association of leisure-time PA with the incidence of AF in White and Black persons older than 65 years of age enrolled in the Atherosclerosis Risk in Communities (ARIC) study, a prospective cohort in the United States.

\section{METHODS}

$\underline{\text { Study Population }}$ 
The ARIC study is a prospective cohort that recruited people 45-64 years of age from 4 communities in the Unites States (Forsyth County, North Carolina; Jackson, Mississippi; Washington County, Maryland; and selected suburbs of Minneapolis, Minnesota) in $1987-1989 .{ }^{8}$ Participants had subsequent study visits in 1990-1992, 1993-1995, 1996-1998, 2011-2013, 2016-2017, and 2018-2019. For this particular analysis, we included participants attending the 2011-2013 (visit 5). We excluded participants with prevalent AF at that visit, those reporting race other than White or Black, as well as non-White participants from the Minnesota and Washington County sites (due to small numbers), and those with missing information on PA or other study covariates (Figure 1). The Institutional Review Boards at each participating ARIC study center approved this study, and all participants provided written informed consent.

\section{Assessment of Physical Activity}

Physical activity was measured with a modified Baecke Physical Activity Questionnaire. The questionnaire asks participants about their leisure, work and sports-related PA over the last year. ${ }^{9}$ Specifically, the questionnaire asks for up to four of the most commons sports or leisure-time activities, as well as the duration and frequency. This information was used to calculate the time (in minutes/week) and intensity (in metabolic equivalent of task [MET] minutes per week) of each activity, and added to obtain weekly levels of moderate to vigorous physical activity (MVPA). ${ }^{10}$

The primary exposure in this study was defined using categories of time spent on MVPA per week according to recommendations outlined by the 2018 Physical Activity Guidelines for Americans. ${ }^{11}$ Specifically, participants were classified in the following groups: no MVPA (reference), $<150 \mathrm{~min} /$ week of moderate physical activity and <75 min/week of vigorous physical activity (low MVPA), 150-299 $\mathrm{min} /$ week of moderate physical activity or 75-149 $\mathrm{min} /$ week of vigorous physical activity or an equivalent combination of MVPA (recommended MVPA), and $\geq 300 \mathrm{~min} /$ week of moderate physical activity or $\geq 150 \mathrm{~min} /$ week of vigorous physical activity or an equivalent combination of MVPA (high MVPA). To combine vigorous and moderate PA, 1 minute of vigorous activity was counted as 2 minutes of moderate 
activity. Thus, someone engaging in $100 \mathrm{~min} /$ week of moderate PA and $30 \mathrm{~min} /$ week of vigorous PA, would be included in the recommended MVPA category $(100+30 \times 2=160 \mathrm{~min} /$ week MVPA).

\section{$\underline{\text { Ascertainment of Incident Atrial Fibrillation }}$}

The main outcome was incident AF between visit 5 and end of 2019 among those without previously diagnosed AF (through the end of 2017 for participants in the Jackson site). AF was identified from electrocardiograms done at study visits 1 through 5, hospital discharge codes ICD-9-CM 427.3x and ICD10-CM I48.x not occurring in the context of cardiac surgery, and from death certificates with AF as underlying or contributing cause of death (ICD-10 I48). ${ }^{12}$

\section{$\underline{\text { Other Covariates }}$}

Age, sex, race, education, smoking (never, former, current) and alcohol (never, former, current) use were self-reported. Height and weight were measured at the time of the study visit and used to calculate body mass index (BMI). Blood pressure was measured three times and the second and third measurements were averaged to calculate systolic and diastolic blood pressure. Hypertension was defined as systolic blood pressure $\geq 140 \mathrm{mmHg}$ or diastolic blood pressure $\geq 90 \mathrm{mmHg}$ or use of antihypertensive medication. Blood glucose was measured in samples obtained during the visit. Diabetes was defined as a fasting blood glucose $\geq 126 \mathrm{mg} / \mathrm{dL}$, non-fasting blood glucose $\geq 200$, use of antidiabetic medication or a self-reported physician diagnosis of diabetes. Prevalent coronary heart disease and heart failure were based on prior history of these conditions using ARIC-specific definitions, as described elsewhere. ${ }^{13,14}$ Physical function was evaluated using the Short Physical Performance Battery (SPPB), an assessment tool for evaluation of lower extremity functioning in older adults, ranging from 0 (worst) to 12 (best function). ${ }^{15}$ We calculated the underlying risk of AF using the Cohorts for Heart and Aging Research in Genomic Epidemiology (CHARGE)-AF score, which provides the 5-year risk of AF based on age, race, height, weight, systolic and diastolic blood pressure, smoking, antihypertensive medication use, diabetes, and history of coronary heart disease and heart failure. ${ }^{2}$

$\underline{\text { Statistical Analysis }}$ 
Statistical analyses were conducted using SAS 9.4 statistical software. In the primary analysis, physical activity was categorized using MVPA cutoffs described above. Additionally, we explored associations of AF with vigorous and moderate physical activity. Categories for vigorous physical activity were $0,>0-74$, and $\geq 75 \mathrm{~min} /$ week and for moderate physical activity were $0,>0-149, \geq 150-299$, and $\geq 300 \mathrm{~min} / \mathrm{week}$. Cox regression models were used to calculate hazard ratios (HR) and 95\% confidence intervals (CI) of AF by levels of MVPA. An initial model adjusted for age, sex, race/center, and education. A second model additionally adjusted for alcohol drinking, cigarette smoking, diabetes, hypertension, prevalent coronary heart disease, prevalent heart failure, BMI, and SPPB. We conducted additional analysis stratifying by race, sex, and the underlying risk of $\mathrm{AF}$, as calculated by the CHARGE-AF score. ${ }^{2} \mathrm{We}$ tested the proportional hazards assumption including interaction terms between exposure and time. No evidence of lack of proportionality in the hazards was found.

\section{RESULTS}

The mean (SD) age for the 5166 eligible participants was 75 (5) years; of them, 59\% were female and $22 \%$ were Black. During a mean (SD) follow-up time of 6.3 (2.0) years, 703 AF events were identified. Table 1 presents patient characteristics by MVPA category (33\% no MVPA, 19\% low MVPA, 25\% recommended MVPA, 23\% high MVPA). Participants engaging in higher levels of MVPA were less likely to be female, Black, and to have a prior history of hypertension, diabetes, or heart failure. Age and predicted risk of AF according to the CHARGE-AF score were similar across MVPA categories.

Table 2 shows the association between MVPA levels and the incidence of AF. There was an overall U-shaped association, with the highest rates in those not engaging in MVPA, lowest among those with low or recommended levels of MVPA, and higher again in those with high MVPA. In the analysis adjusted for demographics, lifestyles and clinical variables, participants engaging in low levels of MVPA had a $23 \%$ lower hazard of AF compared to those in the no MVPA category (HR 0.77; 95\% CI: 0.61 , 0.96). The corresponding figure for those in the recommended MVPA category was $14 \%$ (HR $0.86 ; 95 \%$ CI: 0.69, 1.06). Participants engaging in high levels of MVPA had a risk of AF similar to those with no 
MVPA (HR 0.97; 95\% CI: 0.78, 1.21). Associations were similar in subgroups defined by sex, race, and baseline AF risk, as defined by the CHARGE-AF score (Table 3).

We also evaluated separately the association of moderate and vigorous PA with the incidence of AF (Figure 2). Moderate PA showed an L-shaped association with AF risk, with the highest risk among those not participating in any moderate PA, and the lowest in those participating in $>0-<150 \mathrm{~min} /$ week of moderate PA. There was no evidence of increased risk of AF in participants engaged in $\geq 300 \mathrm{~min} / \mathrm{week}$. The association of vigorous PA with AF risk was U-shaped, with the lowest risk in those participating in $>0-<75 \mathrm{~min} /$ week, and similar risk in those with 0 and $\geq 75 \mathrm{~min} /$ week.

\section{DISCUSSION}

In this large prospective community-based study of individuals older than 65 , we observed that engaging in some degree of MVPA was associated with a reduced risk of developing AF, with less or no benefit among those reporting very high levels of MVPA. The associations were similar across groups defined by sex, race, or underlying AF risk. The beneficial association was observed for intermediate levels of moderate PA and vigorous PA separately, though the limited number of study participants engaging in vigorous PA resulted in imprecise estimates of association. Overall, our findings suggest that engaging even in small amounts of moderate or vigorous PA could reduce the risk of AF among persons 65 and older, and that the risk of AF is not particularly elevated among those with higher levels of PA.

These results from the ARIC cohort are mostly consistent with those reported in other studies. A recent dose-response meta-analysis of the literature including data from 15 studies and over 1.4 million individuals (median age 55 years) also described a U-shaped association, with the lowest risk among individuals engaging in 1000-1500 MET-minutes per week. ${ }^{5}$ Few studies have specifically focused on persons 65 and older. The Cardiovascular Health Study, which followed 5,446 participants 65 and older for 12 years, found that amount of leisure-time physical activity had an inverse linear association with risk of $\mathrm{AF}$ ( $\mathrm{HR}, 0.64 ; 95 \% \mathrm{CI}, 0.52-0.79$, comparing $5^{\text {th }}$ to $1^{\text {st }}$ quintile), while the association between exercise intensity and AF risk was U-shaped, with HR (95\% CI) of AF compared to no exercise of 0.85 
(0.69-1.03) for low intensity, $0.72(0.58-0.89)$ for moderate intensity, and 0.87 (0.64-1.19) for high intensity exercise. $^{7}$

AF risk seems to be higher in athletes and other individuals engaged in intense endurance exercise, particularly younger ones. ${ }^{16}$ In a meta-analysis of 13 studies, including 6,816 athletes and 63,662 controls, the odds of AF were 2.5 higher in athletes compared to controls (OR 2.5; 95\% CI: 1.7-3.5), with the association between being an athlete and AF risk weakening with advancing age. ${ }^{16}$ However, average levels of PA among participants in community-based studies, including ARIC, are generally much lower than those including athletes, making both types of studies difficult to compare.

Engaging in PA could contribute to a reduced risk of AF through multiple mechanisms. PA plays a key role in the prevention and management of several risk factors for AF, including elevated blood pressure, obesity, diabetes, and other cardiovascular diseases (heart failure, coronary heart disease. ${ }^{17}$ By preventing these risk factors, higher levels of PA would result in decreased AF risk over time. We observed, however, that the beneficial association was even present among ARIC participants with a high underlying risk of $\mathrm{AF}$, due in part to presence of AF risk factors. PA could also impact AF risk by directly affecting the atrial substrate responsible for AF development. On the one hand, higher levels of PA in older individuals have been associated with better systolic and diastolic function, in turn preventing the development of the AF atrial substrate. ${ }^{18}$ On the other hand, very high levels of PA could lead to atrial enlargement (but not to atrial mechanical function), ${ }^{19}$ atrial ectopy, atrial fibrosis, increased vagal tone, and changes in electrolytes that can trigger AF or contribute to the development of a susceptible cardiac substrate. $^{20,21}$ The balance between these two opposing pathways may explain the observed U-shaped association between PA and AF risk.

Our findings have relevance for public health guidelines and individual preventive medicine recommendations, by reinforcing current PA guidelines for persons 65 and older and demonstrating absence of harm at those recommended levels in relation to AF risk, even among individuals at higher risk of developing AF. Specifically, the current recommendation to do 150-300 minutes a week of moderate-intensity aerobic PA or 75-150 minutes of vigorous-intensity aerobic PA or an equivalent 
combination was attainable by a large proportion of our study population (close to $50 \%$ were in this category or higher) and was associated with a small reduction in AF risk. Concerns about risk of developing AF should not preclude engaging in moderate levels of PA given the multiple benefits of exercise in the prevention of cardiometabolic diseases and other aging-associated disorders.

The validity of our results is supported by the robust follow-up of the ARIC cohort, with minimal losses to follow-up, the richness of information on relevant covariates, allowing for confounding control, and the diversity of the study population, which facilitated the evaluation of the association separately in males and females, and in Black and White Americans. Some limitations need to be acknowledged, however. Information on PA was self-reported and we did not have objectively measured PA, which is likely to lead to measurement error, non-differential with regards to the study endpoint. AF ascertainment is potentially incomplete, missing subclinical AF as well as AF exclusively managed in an outpatient setting in participants not being hospitalized during their follow-up. This lack of sensitivity in case ascertainment is also likely to be non-differential with regards to PA. Validation studies for the PA assessment and the method of AF ascertainment in ARIC minimize these concerns. ${ }^{12,22}$ Finally, by design, Black participants in the ARIC cohort were recruited primarily at the Jackson site, limiting our ability to separate the effects of race and geographic location.

In conclusion, we observed a U-shaped association between MVPA and AF risk in older persons. These findings support current PA recommendations for this age group and can be used to reassure individuals concerned about AF risk associated with higher levels of MVPA. Future work should aim to understand mechanisms through which PA influences AF risk in this age group, to identify individuals that may particularly benefit from increased levels of PA, and to develop interventions that could reduce the risk of $\mathrm{AF}$ in high-risk individuals.

\section{ACKNOWLEDGEMENTS}

The authors thank the staff and participants of the ARIC study for their important contributions. 
medRxiv preprint doi: https://doi.org/10.1101/2021.12.07.21267411; this version posted December 7, 2021. The copyright holder for this preprint

(which was not certified by peer review) is the author/funder, who has granted medRxiv a license to display the preprint in perpetuity.

It is made available under a CC-BY-NC-ND 4.0 International license.

\section{FUNDING}

The Atherosclerosis Risk in Communities study has been funded in whole or in part with Federal funds

from the National Heart, Lung, and Blood Institute, National Institutes of Health, Department of Health and Human Services, under Contract nos. (HHSN268201700001I, HHSN268201700002I,

HHSN268201700003I, HHSN268201700004I, HHSN268201700005I). Additional support was provided

by the National Heart, Lung, and Blood Institute of the National Institutes of Health under Award

Number K24HL148521 and American Heart Association award 16EIA26410001 (Alonso). The content is solely the responsibility of the authors and does not necessarily represent the official views of the National Institutes of Health.

\section{DISCLOSURES}

None. 


\section{REFERENCES}

1. Virani SS, Alonso A, Aparicio HJ, Benjamin EJ, Bittencourt MS, Callaway CW, Carson AP, Chamberlain AM, Cheng S, Delling FN, et al. Heart disease and stroke statistics-2021 Update: a report from the American Heart Association. Circulation. 2021;143:e254-e743.

2. Alonso A, Krijthe BP, Aspelund T, Stepas KA, Pencina MJ, Moser CB, Sinner MF, Sotoodehnia N, Fontes JoD, Janssens ACJW, et al. Simple risk model predicts incidence of atrial fibrillation in a racially and geographically diverse population: the CHARGE-AF Consortium. J Am Heart Assoc. 2013;2:e00102.

3. Chung MK, Eckhardt LL, Chen LY, Ahmed HM, Gopinathannair R, Joglar JA, Noseworthy PA, Pack QR, Sanders P, Trulock KM. Lifestyle and risk factor modification for reduction of atrial fibrillation: a scientific statement from the American Heart Association. Circulation. 2020;141:e750-e772.

4. Ricci C, Gervasi F, Gaeta M, Smuts CM, Schutte AE, Leitzmann MF. Physical activity volume in relation to risk of atrial fibrillation. A non-linear meta-regression analysis. Eur J Prev Cardiol. 2018;25:857-866.

5. Mishima RS, Verdicchio CV, Noubiap JJ, Ariyaratnam JP, Gallagher C, Jones D, Malik V, Agbaedeng TA, Middeldorp ME, Lau DH, et al. Self-reported physical activity and atrial fibrillation risk: A systematic review and meta-analysis. Heart Rhythm. 2021;18:520-528.

6. Mont L, Elosua R, Brugada J. Endurance sport practice as a risk factor for atrial fibrillation and atrial flutter. Europace. 2009;11:11-17.

7. Mozaffarian D, Furberg CD, Psaty BM, Siscovick D. Physical activity and incidence of atrial fibrillation in older adults: the Cardiovascular Health Study. Circulation. 2008;118:800-807.

8. Wright JD, Folsom AR, Coresh J, Sharrett AR, Couper D, Wagenknecht LE, Mosley TH, Jr., Ballantyne CM, Boerwinkle EA, Rosamond WD, et al. The ARIC (Atherosclerosis Risk In Communities) Study: JACC Focus Seminar 3/8. J Am Coll Cardiol. 2021;77:2939-2959. 
9. Baecke JAH, Burema J, Fritjers JER. A short questionnaire for the measurement of habitual physical activity in epidemiological studies. Am J Clin Nutr. 1982;36:936-942.

10. Palta P, Heiss G, Sharrett AR, Gabriel KP, Walker K, Evenson KR, Knopman D, Mosley TH, Wong DF, Gottesman RF. Mid- and late-life leisure-time physical activity and global brain amyloid burden: the Atherosclerosis Risk in Communities (ARIC)-PET Study. J Alzheimers Dis. 2020;76:139-147.

11. US Department of Health and Human Services. Physical Activity Guidelines for Americans. 2nd ed. Washington, DC: US Department of Health and Human Services; 2018.

12. Alonso A, Agarwal SK, Soliman EZ, Ambrose M, Chamberlain AM, Prineas RJ, Folsom AR. Incidence of atrial fibrillation in whites and African-Americans: the Atherosclerosis Risk in Communities (ARIC) study. Am Heart J. 2009;158:111-117.

13. Loehr LR, Rosamond WD, Chang PP, Folsom AR, Chambless LE. Heart failure incidence and survival (from the Atherosclerosis Risk in Communities Study). Am J Cardiol. 2008;101:10161022.

14. White AD, Folsom AR, Chambless LE, Sharret AR, Yang K, Conwill D, Higgins M, Williams OD, Tyroler HA, The ARIC Investigators. Community surveillance of coronary heart disease in the Atherosclerosis Risk in Communities (ARIC) Study: Methods and initial two years' experience. J Clin Epidemiol. 1996;49:223-233.

15. Guralnik JM, Simonsick EM, Ferrucci L, Glynn RJ, Berkman LF, Blazer DG, Scherr PA, Wallace RB. A short physical performance battery assessing lower extremity function: association with self-reported disability and prediction of mortality and nursing home admission. J Gerontol. 1994;49:M85-94.

16. Newman W, Parry-Williams G, Wiles J, Edwards J, Hulbert S, Kipourou K, Papadakis M, Sharma R, O'Driscoll J. Risk of atrial fibrillation in athletes: a systematic review and metaanalysis. Br J Sports Med. 2021. 
17. 2018 Physical Activity Guidelines Advisory Committee. 2018 Physical Activity Guidelines Advisory Committee Scientific Report. Washington, DC: US Department of Health and Human Services; 2018.

18. Hegde SM, Gonçalves A, Claggett B, Evenson KR, Cheng S, Shah AM, Folsom AR, Solomon SD. Cardiac structure and function and leisure-time physical activity in the elderly: the Atherosclerosis Risk in Communities Study. Eur Heart J. 2016;37:2544-2551.

19. Brugger N, Krause R, Carlen F, Rimensberger C, Hille R, Steck H, Wilhelm M, Seiler C. Effect of lifetime endurance training on left atrial mechanical function and on the risk of atrial fibrillation. Int J Cardiol. 2014;170:419-425.

20. D'Ascenzi F, Cameli M, Ciccone MM, Maiello M, Modesti PA, Mondillo S, Muiesan ML, Scicchitano P, Novo S, Palmiero P, et al. The controversial relationship between exercise and atrial fibrillation: clinical studies and pathophysiological mechanisms. J Cardiovasc Med (Hagerstown). 2015;16:802-810.

21. Peritz DC, Catino AB, Csecs I, Kaur G, Kheirkhahan M, Loveless B, Wasmund S, Kholmovski E, Morris A, Marrouche NF. High-intensity endurance training is associated with left atrial fibrosis. Am Heart J. 2020;226:206-213.

22. Richardson MT, Ainsworth BE, Wu HC, Jacobs DR, Jr., Leon AS. Ability of the Atherosclerosis Risk in Communities (ARIC)/Baecke Questionnaire to assess leisure-time physical activity. Int J Epidemiol. 1995;24:685-693. 
medRxiv preprint doi: https://doi.org/10.1101/2021.12.07.21267411; this version posted December 7, 2021. The copyright holder for this preprint (which was not certified by peer review) is the author/funder, who has granted medRxiv a license to display the preprint in perpetuity.

It is made available under a CC-BY-NC-ND 4.0 International license .

Table 1. Baseline characteristics of study participants by levels of moderate to vigorous physical activity

(MVPA). Atherosclerosis Risk in Communities study, 2011-13.

\begin{tabular}{|c|c|c|c|c|}
\hline & No MVPA & Low MVPA & $\begin{array}{l}\text { Recommended } \\
\text { MVPA }\end{array}$ & High MVPA \\
\hline $\mathrm{N}$ & 1,716 & 961 & 1,289 & 1,200 \\
\hline Age, years & $76(5)$ & $75(5)$ & $75(5)$ & $75(5)$ \\
\hline Female sex & $1,149(67)$ & $617(64)$ & $754(58)$ & $540(45)$ \\
\hline Black race & $527(31)$ & $255(27)$ & $275(21)$ & $97(8)$ \\
\hline At least some college & $559(33)$ & $397(41)$ & $643(50)$ & $722(60)$ \\
\hline Current alcohol use & $644(38)$ & $429(45)$ & $687(53)$ & $807(67)$ \\
\hline Current smoking & $135(8)$ & $44(5)$ & $74(6)$ & $57(5)$ \\
\hline BMI, $\mathrm{kg} / \mathrm{m}^{2}$ & $30(6)$ & $29(5)$ & $28(5)$ & $27(5)$ \\
\hline Diabetes & $669(39)$ & $319(33)$ & $339(26)$ & $271(23)$ \\
\hline Hypertension & $1377(80)$ & $732(76)$ & $898(70)$ & $768(64)$ \\
\hline Prevalent CHD & $230(13)$ & $106(11)$ & $162(13)$ & $169(14)$ \\
\hline Prevalent heart failure & $230(13)$ & $123(13)$ & $102(8)$ & $76(6)$ \\
\hline SPPB, score & $8.5(2.8)$ & $9.1(2.5)$ & $9.8(2.1)$ & $10.3(1.8)$ \\
\hline CHARGE-AF 5-year risk, \% & $12(10)$ & $12(11)$ & $11(9)$ & $11(10)$ \\
\hline 5-year risk $>10 \%$ & $793(46)$ & $390(41)$ & $501(39)$ & $504(42)$ \\
\hline \multicolumn{5}{|l|}{ Physical activity measures } \\
\hline MVPA, min/week & $0(0)$ & $88(42)$ & $223(40)$ & $434(127)$ \\
\hline Moderate PA, min/week & $0(0)$ & $87(43)$ & $220(48)$ & $383(151)$ \\
\hline Vigorous PA, min/week & $0(0)$ & $1(5)$ & $3(16)$ & $52(95)$ \\
\hline
\end{tabular}

Values correspond to mean (standard deviation) for continuous variables and $\mathrm{N}$ (percentage) for

categorical variables. BMI: body mass index. CHD: Coronary heart disease. PA: Physical activity. SPPB:

Short Physical Performance Battery score. MVPA categories defined as no MVPA ( $0 \mathrm{~min} / \mathrm{week}$ of 
moderate or vigorous physical activity), low MVPA ( $<150 \mathrm{~min} /$ week of moderate physical activity and $<75 \mathrm{~min} /$ week of vigorous physical activity), recommended MVAP (150-299 min/week of moderate physical activity or 75-149 min/week of vigorous physical activity or an equivalent combination of MVPA), and high MVPA ( $\geq 300 \mathrm{~min} /$ week of moderate physical activity or $\geq 150 \mathrm{~min} /$ week of vigorous physical activity or an equivalent combination of MVPA). 
Table 2. Association of moderate to vigorous physical activity (MVPA) levels with incidence of atrial fibrillation (AF). Atherosclerosis Risk in Communities study, 2011-2019.

\begin{tabular}{|l|l|l|l|l|}
\hline & No MVPA & Low MVPA & Recommended & High MVPA \\
& & & MVPA & \\
\hline AF events & 268 & 112 & 156 & 167 \\
\hline Person-years & 10,338 & 5,980 & 8,323 & 7,933 \\
\hline IR (95\% CI)* & $26(23,29)$ & $19(15,23)$ & $19(16,22)$ & $21(18,24)$ \\
\hline & \multicolumn{5}{|c|}{ HR (95\% CI $)$} & $0.80(0.65,0.99)$ \\
\hline Model 1 & 1 (ref.) & $0.73(0.59,0.91)$ & $0.73(0.59,0.89)$ & $0.97(0.78,1.21)$ \\
\hline Model 2 & 1 (ref.) & $0.77(0.61,0.96)$ & $0.86(0.69,1.06)$ & \\
\hline
\end{tabular}

* Incidence rate per 1,000 person-years.

AF: atrial fibrillation. CI: Confidence interval. HR: Hazard ratio. IR: Incidence rate.

Model 1: Cox proportional hazards model adjusted for age, sex, race/center and education.

Model 2: Cox proportional hazards model adjusted for Model 1 variables and alcohol drinking, cigarette smoking, diabetes, hypertension, prevalent coronary heart disease, prevalent heart failure, body mass index, and Short Physical Performance Battery score. 
Table 3. Hazard ratios and 95\% confidence intervals of atrial fibrillation (AF) for categories of moderate to vigorous physical activity (MVPA) by sex, race, and baseline risk of AF. Atherosclerosis Risk in Communities study, 2011-2019.

\begin{tabular}{|c|c|c|c|c|c|}
\hline & No MVPA & Low MVPA & $\begin{array}{l}\text { Recommended } \\
\text { MVPA }\end{array}$ & High MVPA & $\mathrm{P}$ for interaction \\
\hline & \multicolumn{4}{|c|}{ HR $(95 \% \mathrm{CI})$} & \\
\hline \multicolumn{6}{|l|}{ Sex } \\
\hline Female & 1 (ref.) & $0.76(0.57,1.01)$ & $0.89(0.67,1.17)$ & $0.89(0.64,1.23)$ & 0.82 \\
\hline Male & 1 (ref.) & $0.76(0.53,1.08)$ & $0.83(0.60,1.14)$ & $1.03(0.76,1.40)$ & \\
\hline \multicolumn{6}{|l|}{ Race } \\
\hline Black & 1 (ref.) & $0.57(0.32,1.04)$ & $0.70(0.39,1.27)$ & $0.48(0.17,1.38)$ & 0.49 \\
\hline White & 1 (ref.) & $0.80(0.63,1.02)$ & $0.89(0.71,1.11)$ & $1.02(0.81,1.28)$ & \\
\hline \multicolumn{6}{|c|}{$\begin{array}{l}\text { Baseline } \mathrm{AF} \\
\text { risk }\end{array}$} \\
\hline$<10 \%$ & 1 (ref.) & $0.80(0.56,1.15)$ & $0.86(0.62,1.20)$ & $0.78(0.54,1.15)$ & 0.20 \\
\hline$\geq 10 \%$ & 1 (ref.) & $0.74(0.56,0.99)$ & $0.83(0.63,1.09)$ & $1.06(0.82,1.38)$ & \\
\hline
\end{tabular}

Cox regression models adjusted for age, sex and race/center (if applicable), education, alcohol drinking, cigarette smoking, diabetes, hypertension, prevalent coronary heart disease, prevalent heart failure, body mass index, and Short Physical Performance Battery score. 
medRxiv preprint doi: https://doi.org/10.1101/2021.12.07.21267411; this version posted December 7, 2021. The copyright holder for this preprint (which was not certified by peer review) is the author/funder, who has granted medRxiv a license to display the preprint in perpetuity. It is made available under a CC-BY-NC-ND 4.0 International license.

Figure 1. Study inclusion flowchart, Atherosclerosis Risk in Communities study. AF: atrial fibrillation

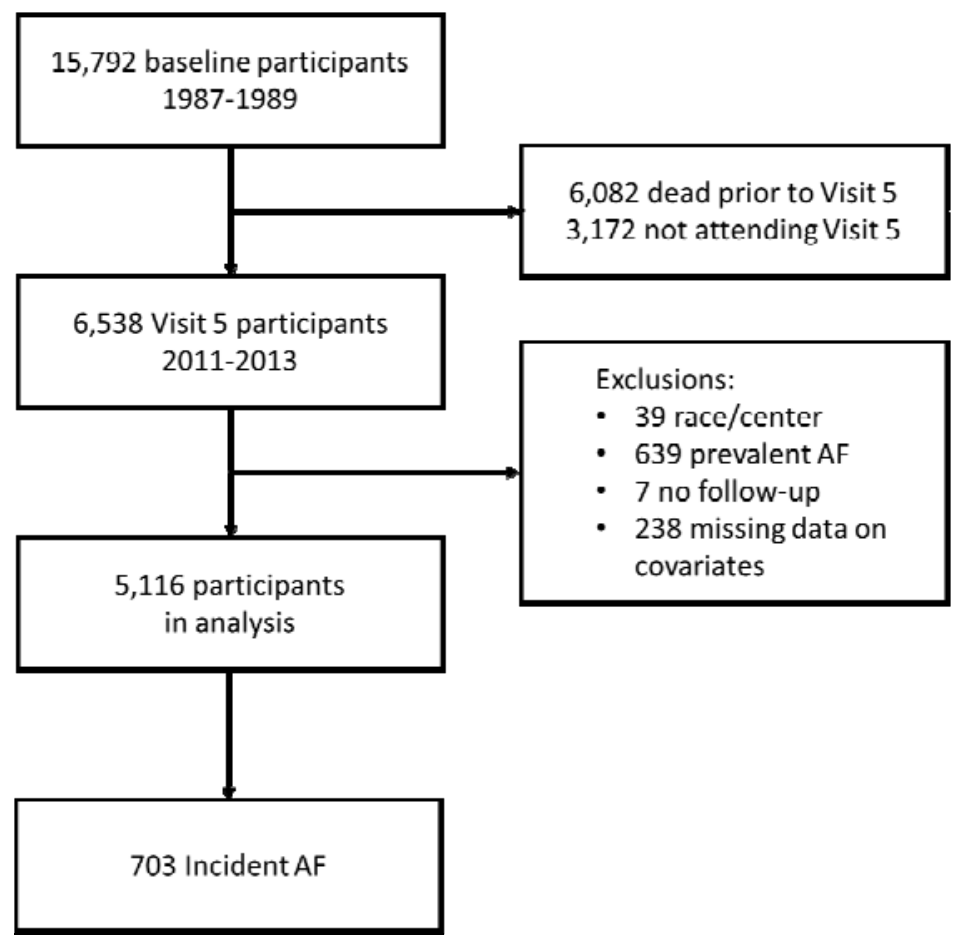


Figure 2. Hazard ratios and 95\% confidence intervals of atrial fibrillation (AF) for categories of moderate and vigorous physical activity (PA). Model 1 is a Cox regression model including moderate and vigorous PA categories in the same model adjusted for age, sex, race/center, and education. Model 2 additionally adjusts for education, alcohol drinking, cigarette smoking, diabetes, hypertension, prevalent coronary heart disease, prevalent heart failure, body mass index, and Short Physical Performance Battery score. Atherosclerosis Risk in Communities study, 2011-2019.

Model 1

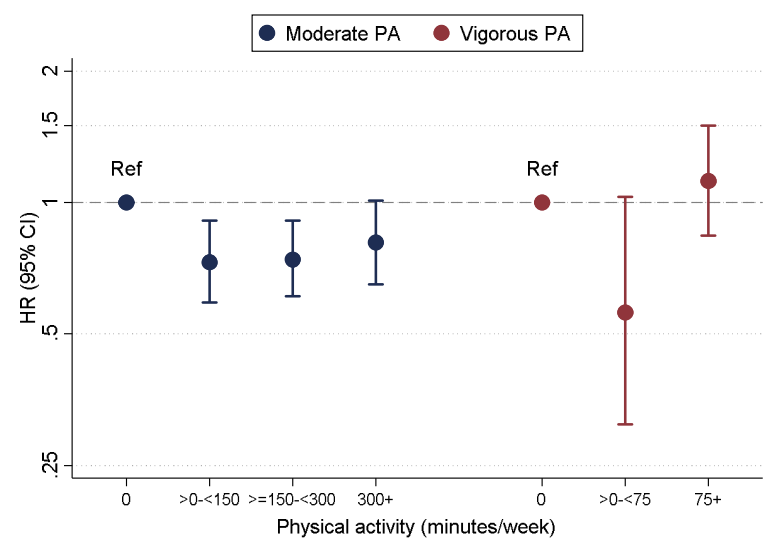

Model 2

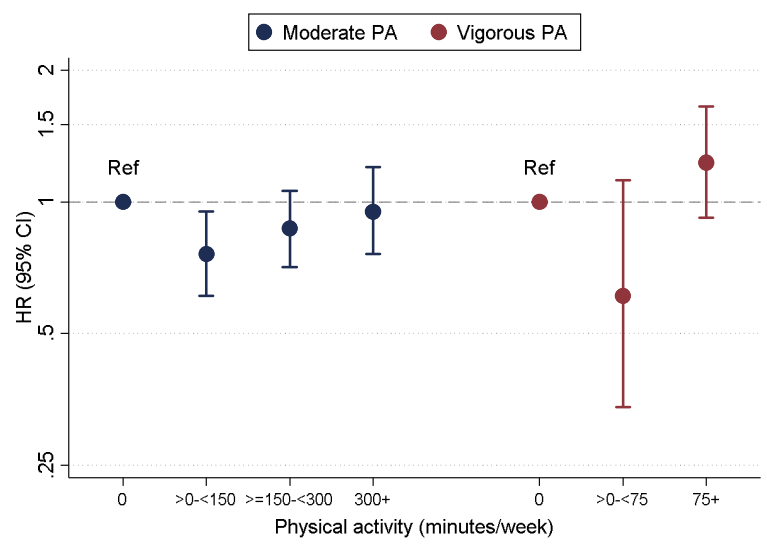

